\title{
ERRATUM: Single-molecule analysis of human telomerase monomer
}

David Alves, Haitao Li, Rosalind Codrington, Angel Orte, Xiaojun Ren, David Klenerman \& Shankar Balasubramanian Nat. Chem. Biol. 4, 287-289 (2008); published online 6 April 2008; corrected after print 1 May 2008

In the version of this article initially published, parentheses were missing around covalently attached domains in fusion proteins. Also, in the first two lines of the left column of page 288, "hTERT-YFP" should have read "YFP-hTERT" for consistency with the rest of the manuscript. The errors have been corrected in the HTML and PDF versions of the article.

\section{CORRIGENDUM: NFKB selectivity of estrogen receptor ligands revealed by comparative crystallographic analyses}

Kendall W Nettles, John B Bruning, German Gil, Jason Nowak, Sanjay K Sharma, Johnnie B Hahm, Kristen Kulp, Richard B Hochberg, Haibing Zhou, John A Katzenellenbogen, Benita S Katzenellenbogen, Younchang Kim, Andrzej Joachimiak \& Geoffrey L Greene Nat. Chem. Biol. 4, 241-247 (2008); published online 16 March 2008; corrected after print 1 May 2008

In the version of this article initially published, the 13th author's last name is misspelled. The author's name should read 'Andrzej Joachimiak'. Additionally, Figure 5 of this article inadvertently contains pink traces in each panel that are not attributed to any specific molecule. The corrected figure (missing these traces) is shown here. These errors have been corrected in the HTML and PDF versions of the article.

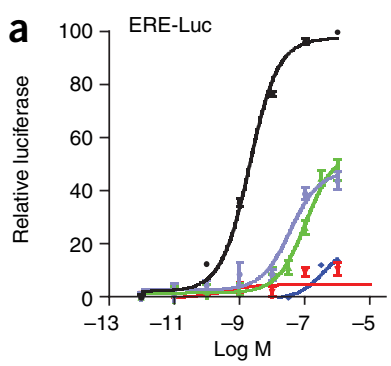

- E2

$\triangle$ Indazole

- PhIP

- Pyrazolopyrimidine

$\checkmark$ Diethyl oxabicyclic
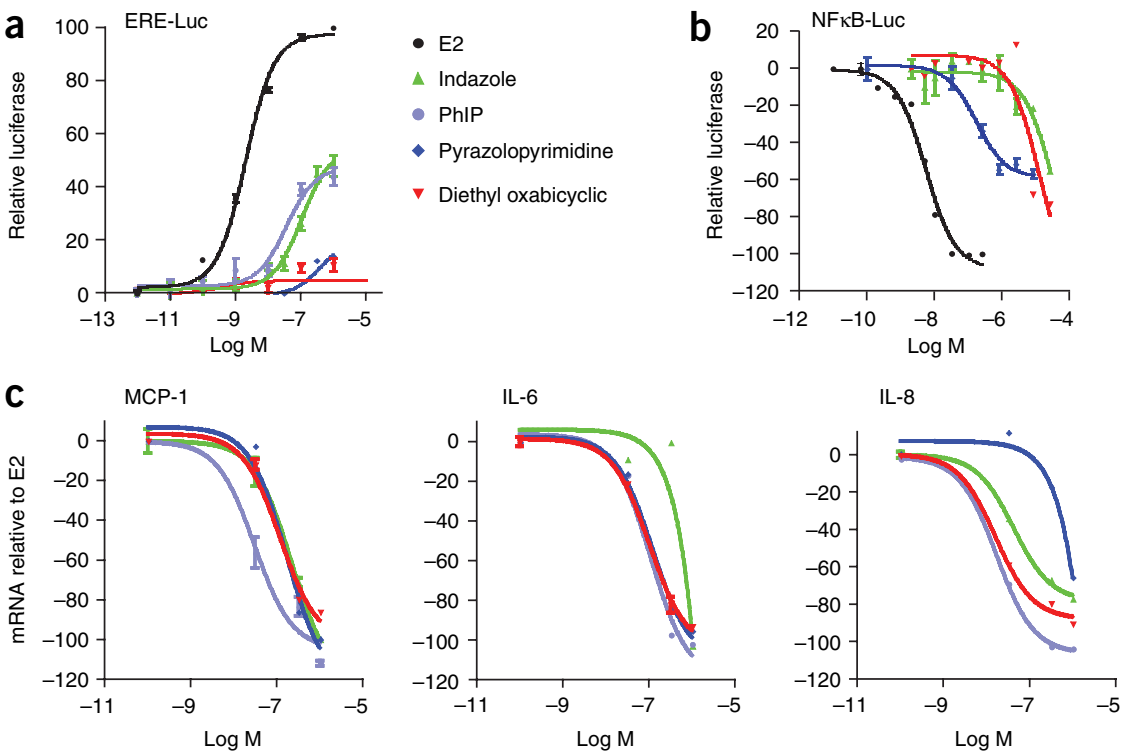